\title{
Walking the tight rope: Women's health social workers' role with vulnerable families in the maternity context
}

\author{
Linda Haultain ${ }^{1}$, Christa Fouche ${ }^{2}$, Hannah Frost ${ }^{1}$ and Shireen Moodley ${ }^{1}$
}

\footnotetext{
${ }^{1}$ Auckland District Health Board, New Zealand

${ }^{2}$ Associate Professor, University of Auckland, New Zealand
}

\begin{abstract}
INTRODUCTION: Keeping children in the centre of practice is an established mantra for the children's workforce internationally and is also enshrined in the Aotearoa New Zealand Children, Young Persons and Their Families Act 1989. The principle that the welfare and interests of the child are awarded paramount consideration (s6) when these are in conflict with others' needs is incontestable. However, we suggest that how this translates into day-to-day social work practice is open to multiple interpretations. This interpretation emerged from a women's health social work team, providing services to pregnant women experiencing complex social factors.
\end{abstract}

METHOD: An audit collected and analysed data from cases that were identified as having achieved successful outcomes in this context. A metaphor emerged from the reflective analysis of these findings. This metaphor, 'walking the tight rope, maintaining the balance' was put to the practitioners via a reflective process.

FINDINGS: Research findings indicate that by taking up a child welfare orientation to practice positive outcomes are possible. This practice was found to rely on a number of personal, professional and organisational factors, most dominant were those associated with relationship based practice. Findings suggest that women's health social workers need to maintain a fine balance with several critical elements, such as the provision of reflective supervision acting as a practice safety net.

CONCLUSION: It is argued that the binary either/or positions of adopting a child centred or a woman's centred approach to practice should be avoided and an and / both orientation to practice be adopted. This reflects a child welfare orientation to practice - one in which prevention is a primary focus.

KEYWORDS: women's health; maternity care; child welfare; vulnerable children; children's workforce; relationship-based practice

\section{Introduction}

Responding to the needs and vulnerabilities that pregnant women, babies, and children are experiencing, for the most part occurs during the period of pregnancy in a women's health maternity environment. This demands that women's health social workers (WHSW) develop responses to child vulnerability that are appropriate in these circumstances; that is, that they are able to support the pregnant woman's ongoing engagement with her maternity care provider, while also responding to the complex social factors that impact her and her baby's safety and wellbeing.

For everyone practicing in this context, there is an increasing focus on the contribution we can make to help improve the health 
and wellbeing of vulnerable infants. This is evident by the Aotearoa New Zealand (ANZ) government's policy direction which includes initiatives such as the Children's Action Plan (CAP) and its associated activities. Most specific to this policy direction has been the advent of Maternity Care, Wellbeing and Child Protection Multi-Agency Groups in all District Health Board maternity services, signalling that child welfare is the responsibility of multiple agencies. Although not presenting new ideas, the CAP places great emphasis on terms such as working together and sharing the responsibility for vulnerable children and their families. How we orientate our practice to make this particular contribution in a maternity context is the subject of this article.

In women's health, a firm link has been established between the social determinants of health, for example access to maternity care (Barnes et al., 2013) and the significant health impacts of living in highly disadvantaged social situations (Bywaters, McLeod, \& Napier, 2009). Bywaters argues that "health should be a central concern for social workers because it is an issue of social justice, affecting the way people live" (Bywaters, 2014, p. 28). In ANZ we have been made acutely aware of the effects of poverty on infants and children - with inequality and its impact on their lives being described as a New Zealand crisis (Rashbrooke, 2013). Adverse outcomes associated with living in poverty include poor physical and mental health, exposure to harmful occurrences such as substance misuse, domestic abuse, and crime (Handcock, 2013). Coalitions such as the Child Poverty Action Group also draw our attention to ANZ children's plight, arguing that prevention is the best way to address child poverty (O'Brien, 2015).

Registered social workers are required to ensure that their practice reflects their obligations to the professional codes of ethics, and practice standards established by professional bodies. The ability to respond to vulnerability and risk, situated within an ethical framework identifies a number professional obligation (International Federation of Social Workers, 2008). These include the responsibility to uphold and defend each person's psychological and emotional integrity and wellbeing; respect their right to self-determination; recognise the UN Convention on the Rights of the Child (1989) and also to recognise the UN Convention on the Elimination of all forms of Discrimination against women (1979) (Haultain, 2014). How we achieve these aims, is partially dependent on the context in which the practice is occurring, impacting where the emphasis is prioritised.

\section{Child protection orientation}

Writing about system design, vulnerability and ethics Keddell (2014) introduces the idea of political genres (Gilbert, Parton, \& Skivenes, 2011). She suggests that the ways we think about the world "broadly affect the framing of systems, the provision of services, and beliefs about what is good and proper, in short, what is considered ethical" (Keddell, 2014, p. 2). Expanding on what she refers to as flavour differences between various orientations, Keddell (2014) proposes that a key characteristic of the child protection orientation is that problems are framed in moralistic and individualistic ways - with a strong focus on investigatory interventions. Relying on Fargion (2014) Keddell (2014) argues that when our practice is informed by this child protection orientation, the best interests of the child may be quite narrowly defined-with the primary focus on protection.

Alternatively, if we adopt a child welfare orientation it is one that is largely concentrated on prevention, as a counter to a focus on risky events. Fargion (2014) suggests that the essence of the child welfare approach is the desire to help "create those material and social conditions within which all children are given sufficient opportunities to reach their full potential" (p. 25). One of the things this approach relies on is the 
capacity to explore both the strengths and resources in a family, as well the difficulties they may be experiencing.

Multiple critiques of the child protection oriented system have been proposed both locally (Dobbs \& Eruera, 2014; Hyslop, 2009; Turnell, 1989) and internationally (Beddoe, 2014; Featherstone, White, \& Morris, 2014; Ferguson, 2001, 2003; Gould \& Baldwin, 2006; Laing \& Humphreys, 2013; Lonne, Parton, Thomson, \& Harries, 2009; Munro, 2011). A consistent concern is the prevalence of indigenous children who come to the attention of child protection authorities, and the predominantly Western approach taken to responding to their needs. Many of these authors also make an explicit connection between the current neo-liberal ideology and its broad impact on the approaches we take to child protection practice.

Arguing for the radical reforming of the practices that aim to improve the safety and wellbeing of children these and other authors suggest that current systems and processes have failed. Critical of the increasing mechanisation of practice and the negative impacts of regulation and inspection, they suggest this results in the shift away from reflective practice, and a move towards the management of practice via the use of technocratic practice tools (Featherstone et al., 2014; Ferguson, 2003; Lonne et al., 2009). Lonne et al. (2009) are also critical of narrow interpretations of child protection practice which fail to situate the child's overall safety and well-being within the context of their family. They advocate a child welfare approach to practice. These critiques, the worst of which play out to a greater or lesser extent in the women's health practice environment, raise a number of questions for WHSWs, including how to navigate the multiple ethical responsibilities WHSWs carry. These include the obligations in relation to the human rights associated with access to health care, and the responsibilities connected with child safety and wellbeing.

\section{Study Design}

This study was lead by the Social Work Professional Leader at Auckland District Health Board. Women's Health Social Work Practice Supervisors made up the research team with practice based research mentorship and editing provided by Christa Fouche. In order to help articulate an approach to practice in this context, we engaged in an "...examination and interrogation of the professional activities and their effects" (Featherstone, et al., 2014, p. 53) via a series of practice based research activities (Epstein, 2010). These activities are characterised by practitioners (in this case Professional Leader and Practice Supervisors) using agency data to engage in research that has direct implications for practice (Blumenfield \& Epstein, 2001). Writing about critical best practice Ferguson (2003) defines this attitude of inquiry as solution focused. It aims to provide positive resources to practitioners - but in a way that takes account of various ethical obligations, including those associated with power and inequalities. Ferguson is clear that we are not engaging in "some unqualified celebration of 'good works', but a standard for the evaluation of 'best' practice which is rigorously, sociologically critical" (Ferguson, 2003, p. 1006). Ferguson describes how social workers "... work creatively with, and within structures to carve out actions which make a positive difference to service user's lives" (Ferguson, 2003, p. 1006). We share Ferguson's desire to show case practice that makes a positive difference to the lives of pregnant women, their children and families and therefore implemented this approach in the interrogation of the model of care in the WHSW team.

Findings from a doctoral study that identified the dimensions of effective health social work in an acute hospital setting were utilized to develop an audit tool (Haultain, 2011). The audit, conducted by the Social Work Professional Leader, and two Practice Supervisors of the WHSW team, was regarded as a quality activity and therefore did not 
require ethics approval. The subsequent reflective process was assessed as a low risk activity - given the appreciative and practicebased nature of the discussion and the choice practitioners were given to participate.

The audit tool was applied to analyse three cases. A sub-set of the dimensions of effective health social work practice were selected from Haultain's (2011) doctoral study in the design of the audit tool. These were assessed as most critical to the provision of what Featherstone and her co-authors refer to as "...family-minded, humane social work practice" (Featherstone et al., 2014, p. 53). The study by Haultain (2011) has established that central to the role of effective health social work practice in the acute hospital setting is the capacity to respond to the various safety issues and vulnerabilities patients experience across the lifespan. It was understood that these vulnerabilities are associated with multiple elements of a family's social situation, which include their access to, and engagement with health services. A central finding of Haultain's study, relevant to maternal health and the audit tool, is that, while responding to these vulnerabilities the capacity to engage in relationship based practice (RBP) is critical (Haultain, 2011). Broadly speaking this sub-set of activities, attitudes and behaviours grouped into the category of relationship based practice (RBP) were applied in the context of responding to vulnerability and risk in the women's health environment. The audit tool is available on request.

The next step in the audit process was developing selection criterion, as to focus attention on the cases that had the greatest potential to demonstrate best practice within the context of very limited resources. This also aligns with the principles in the application of rapid tests of practice via the Plan, Do, Study and Act (PDSA) cycle, recommended as a quality tool that is able to bring improvement of practice straight to the front line (Lachman \& Bernard, 2006). The case selection was straightforward in selecting three cases that the practice supervisors assessed as good practice, the tangible measure for this was that the pregnant woman remained engaged throughout her pregnancy with the maternity health care providers, and that her baby was born safely. These criteria reflect the multiple ethical responsibilities the WHSW team carry in regards to ensuring ongoing access to health care, and attention to children's safety and wellbeing.

The clinical record of the three selected case studies were next considered against the dimensions of the audit tool so as to understand the quality and nature of the activities, attitudes and behaviours of the WHSW team. The clinical record itself is made up of a number of documents, including the initial referral; completed assessment documents; reports of concern to CYF; emails and accounts of phone calls; ward and multi-agency plans; and alert documentation and running notes, many of which recorded conversations with the women. In total six hours of reading and analysis occurred for each case. The time this took suggests three primary factors: the length of practitioners' involvement with the women (on average six months); the intensive nature of the work (a WHSW on average has 12-14 cases of this type); and the level of complexity and risk WHSW were responding to - suggesting that careful documentation is an essential element of good care.

Numerous reflective conversations about the audit findings then occurred between the Social Work Professional Leader, and two Practice Supervisors which formed the second phase of the study. A metaphor emerged from the audit findings as a result of these conversations; this was tested for its relevance - as the third phase of the study - in a reflective focus group activity with WHSW practitioners. The entire study developed over a four year period during which time some personnel changed. The participants (seven) in the reflective conversations were made up of the current WHSW team of practitioners and practice supervisors. 


\section{Findings}

\section{Phase 1: The audit}

Two main themes emerged from the first phase of the study, namely relationshipbased practice and cultural responsiveness. These themes will be discussed in this section.

\section{Relationship-based practice}

The main practice orientation that emerged from the audit (and which was driven by various external factors), is the importance of relationship based practice (RBP) with a strong child welfare orientation. This practice focused on attending to the issues that were impacting the pregnant woman's safety and wellbeing (and therefore her baby), while also focusing on the preservation of the relationship.

The practices documented in the clinical record that best reflects this orientation included evidence of trust, rapport, safety and confidence. This became evident through the following examples: informed consent being gained inclusive of the limitations of confidentiality being outlined; assessments were complete to the expected standard, including a focus on safety, vulnerability, needs and risk; sensitive information was shared, discussed and responded to; history was taken into account, but was kept in its place - assessed as one of the drivers of practice responses; reports of concern to CYF were written with the women's knowledge; and cultural needs were identified and responded to in partnership with cultural support services.

Evidence that extensive advocacy with other agencies was undertaken was also noted, while relationships were maintained with both the woman client and the agency staff. Much of this activity reflected the practitioner's efforts to develop a shared understanding with other agencies about the issues in play, and to agree plans. Despite what was often an obvious difference of approach or opinion, the desire to engage in respectful communication, also with the aim of safeguarding the interagency relationship was evident.

Extensive use of supervision and consultation was recorded which included the cases being taken to various multidisciplinary and multiagency forums. Multiagency intervention and safety plans were developed with the woman, their partners and families. Also evident were the practical needs that were responded to including food, housing and baby needs. It was evident that throughout the episode of care cultural and spiritual issues were proactively explored and attended to.

\section{Cultural responsiveness}

Significant evidence of cultural responsiveness in practice prompted more in-depth consideration of how obligations in relation to bi-cultural practice documented in the clinical records, could be structured and described for the purpose of the audit findings. It was agreed to do this through the lens of social worker's Treaty of Waitangi obligations ${ }^{1}$ which include the practice principles of partnership, participation and protection. This allowed the detail of how these important principles actually manifest in practice, to be captured. Due to the scope of this article, not all this information can be reported here, but is the focus of another article under development. Some examples are described in table 1.

\section{Phase two: Reflective conversations}

A process of ongoing reflection of data collated through the audit enabled the correspondence between the dimensions of practice to be described in new ways (Creswell \& Plano Clark, 2011). Having

Social Workers in ANZ are bound by a professional Code of Ethics; central to this code are our bicultural practice obligations which emerge from responsibilities enshrined in the Treaty of Waitangi. 
Table 1. The Treaty of Waitangi principles in practice

\begin{tabular}{|l|l|l|}
\hline Partnership & Participation & Protection \\
\hline Women were given information and choices & $\begin{array}{l}\text { Advocacy with other services associated } \\
\text { with supporting women's participation }\end{array}$ & $\begin{array}{l}\text { Relationships with women, other agencies and } \\
\text { babies were protected }\end{array}$ \\
\hline Work alongside cultural support workers & Explaining things in plain English & Cultural advocacy and support were provided \\
\hline $\begin{array}{l}\text { Use of meetings, including with partners } \\
\text { and wider whanau }\end{array}$ & $\begin{array}{l}\text { Taking things slowly, not giving up when } \\
\text { things got tricky }\end{array}$ & $\begin{array}{l}\text { Babies access to breast milk was supported } \\
\text { as were contact arrangements, and where } \\
\text { appropriate restitution of the child to the mother }\end{array}$ \\
\hline Making plans together & Making plans together & Cultural practices such as memory making occurred \\
\hline Keeping women in the centre (relationally) & Sharing decision making & $\begin{array}{l}\text { If baby was to be removed, careful plans } \\
\text { reflected respect and compassion }\end{array}$
\end{tabular}

interrogated three cases and established what Ferguson (2003) describes as the critical practices that were 'best', it was considered important to understand from the practitioners themselves, in addition to the findings from the clinical records, the broader context of practice. In order to do this, reflective conversations occurred between the members of the audit team. A metaphor developed from these reflective conversations. This metaphor: Walking the tight rope - maintaining the balance reflected the findings of the audit and the significant efforts that were made to maintain the balance of women's needs and their babies' needs, in a culturally responsive way. This appeared to be achieved by keeping the relationship with women at the forefront of practice.

This notion of balancing various factors and practice vulnerability brought forward the concept of a practice safety net. It was hypothesized that some of what enabled the WHSW team to maintain this balance was the personal, professional and organisational safety net that underpins practice. The strands of this safety net were explored in the next phase of the study.

\section{Phase three: Focus group}

The final phase of the study was to explore the themes of 'balance' and 'safety net' which developed from phase 2, with the full WHSW team and practice supervisors (seven participants in total) in a focus group. The focus group facilitator put the question to practitioners: when you reflect on working with pregnant women who are experiencing significant child protection concerns what are the personal, professional and organisational factors that you believe have a bearing on the ability you have to maintain this balance? What followed was a facilitated series of questions, with time for practitioners to write answers, and engage in rich conversation. A general inductive approach was utilised for data analysis in this phase, which Thomas describes as a systematic process whereby the detailed reading of raw data enables the researcher to derive particular concepts, and allows themes and models to emerge over time (Thomas, 2006).

By highlighting phrases, and grouping content into categories, each of which was coded and aggregated into a pattern category - the framework for the WHSW practice model and its foundations was strengthened and the themes of balance and safety net developed in phase 2 of the study, were further developed. These four categories comprise firstly, personal values and beliefs systems; secondly professional influences, thirdly the organisational factors and lastly, elements that put the balance at risk. These four components will be outlined next. 


\section{Personal values and belief systems}

Personal value systems that include a commitment to feminist values, cultural awareness, and social justice all featured strongly in the data. These values appeared to be at the foundation of practice for the WHSW team. All participants talked about social disadvantage and its impact on women and their families acknowledging that many of their clients identify as Māori or Pacific in origin. It was also understood that these populations are more significantly impacted by economic and cultural variables associated with inequality.

A fundamental belief in each woman's innate value was expressed, with practitioners' orientation towards their client's rights, strengths and capacity standing out. The thematic analysis highlighted that it is these fundamental values and beliefs that impact how practitioners engage with women. Practitioners were careful to stress that their way of being with women was about connection - not collusion. This reinforced what was observed in the audit, which was that the hard conversations were courageously initiated, but that this was done in a particular way. Guided by a mix of personal and professional attributes such as empathy, generosity, kindness, compassion, fairness and patience, the relationship was attended to while the difficult conversations occurred.

An ethic of supporting self- determination and a desire to not add to the woman's disadvantage was found to be central to maintaining the balance. One practitioner expressed a "willingness to hear her whole story while appreciating I can't ever know her whole story." The valuing of women was evident in a number of the descriptions reflecting an understanding that often this required the ability to persevere, and to be patient.

"Women have value, even when they are unable to step into the space we offer and hold (for healing and recovery), we still offer that space, and continue to offer it" expressed another practitioner. This notion of valuing of women was extended into the professional realm expressed as "I want to know you, as you are and this requires a suspension of judgement." These reflections lead to an inquiry about how this attitude of empathy and a willingness to invest in women, helps to shape the practice.

It became apparent in conversation with the team that it was important to them to not add to the suffering the women had already experienced. Empathy as a personal value in practice meant being able to wonder "what was that experience like?" and to be willing to "hold a broader, and a longer view" - by engaging women in conversations about their hopes and dreams - setting the stage for the development of goals that were meaningful and relevant to the woman and her child, or children. This willingness to look both backwards (reviewing history) but also look forward (holding hope for the future) was a central feature of practice - with a senior member of the team reflecting that "it's not just about now." Having established the foundations of practice, we were curious to discover was practice models, or theoretical influences informed the practice, and here it became evident that some models were preferred over others.

\section{Professional influences}

A second theme to surface in the analysis of the data from the focus group was the knowledge, skills and supervisory discussions practitioners relied on to help inform and shape their practice. Participants described a vast array of professional influences which they felt best enabled them to reflect their personal and professional values in practice. These included descriptions such as women centred and family centred care; the social model of health; and cultural responsiveness. This quote, from a practitioner who herself is from an ethnic minority described it this way, "my position as someone from an 
ethnic minority, it helps me to be empathic, to be aware of Pakeha [Western] models, the medical model and ways of thinking, it helps me to have a strong voice, to advocate for women from minorities."

Strength based practice, including the influences of narrative therapy also featured, with a sustained focus on trauma informed practice. A thorough knowledge of attachment theory, and the ability to notice and respond if the mother and baby relationship was in trouble, were evident. The ability to assess the level of harm a pregnant woman may be exposed to also feature strongly, as did a range of professional skills. The ability to facilitate conversations with parents, wider family, and the capacity to work constructively with conflict was strongly relied on. Compassionate listening, rapport building skills, and the capacity to build trust and confidence that supported the relationship were described as central. A well-developed ability to engage in both multi-professional and multiagency working was evident, with a sound understanding expressed regarding the need to work together in order to maintain the balance of needs.

A final pillar of the professional influences, which reinforced the audit findings, was the rigorous use of consultation and supervision, this included seeking cross cultural support. Describing the value of supervision one practitioner felt that it was "less about the specifics of a case - and more about the telling - it is in the telling that the gaps and strengths of practice can be identified." Others described the importance of the reflective opportunity supervision provides, with one practitioner explaining "there is a chance for me to be curious about my own practice, asking myself the how and the why questions." Another practitioner talked about the importance of the supervisor's skills, and of feeling safe. She described how "they have skills, knowledge and understanding that they offer to the practice, they also offer the care and support."
The supervisor was also portrayed by a practitioner as "the bigger, stronger, kinder person, they provide that space for us and that enables us to hold that space for others (clients)."

The supervisory process and relationship at its best was richly described by a participant as a place where "permission giving occurred - I am allowed to make mistakes, to innovate, to explore and extend my practice." Another explained how "it (supervision) is not risk averse - we make decisions together and we hold risk together." It was important that supervisors were "not black and white... where not rigid." What was outlined as valuable was the ability to "honestly and safely explore the tensions" to be "able to engage in a reflective inquiry, and to collaborate to make decisions together about where to next." Lastly supervision was described as "competent - safe and informed - it's a high trust environment." The final theme from the focus group that developed the understanding of 'balance' and 'safety net' are those aspects associated with organisational factors.

\section{Organisational factors}

A number of important organisational factors emerged as central to maintaining the balance of practice in this context. These included many of the elements that we associate with professional and clinical governance, or the organisational investments that allow standards to be set and excellence to flourish.

This included for the practice supervisors, elements of clinical audit and a reflective gaze over practice being maintained on a regular basis. This was achieved via a number of mechanisms, many of which occur as part of the annual performance appraisal process. The live observation of practice, an audit of clinical notes, the review of supervision and continuing professional development logs - all were described as enabling and supporting a detailed review of 
the practice. Recognition of the value of investment in training, attendance at journal club and time being protected "for reflection" was also highlighted.

Agreement about an appropriate case load size, and careful workload management was perceived as vital - adding weight to the value of having enough time to do a good job. The capacity to seek advice and information from multiple forums and the expectation expressed as "we share decision making with our multiagency colleagues" was also central to helping to keep the practice safe, and on track. What also featured in this organisational context were a number of key policies that help shape and inform practice expectations, including ones on child protection, informed consent, supervision and the social work assessment policy.

Clearly these conversations were appreciative in orientation, aiming to describe the best of what's possible, rather than attempting to claim it as a solid truth, by saying "it's always like this." It also felt important to enquire about the times when the balance could be put in jeopardy. The team were able to clearly describe when things got shaky up there on the tight rope the next section reflects the findings related to their account of these times.

\section{Elements that put the balance at risk}

One of the greatest risks to maintaining the balance was what a practitioner described as "not being able to develop a shared understanding of the issues, concerns and strengths of the client's situation." Times when there was a "lack of willingness to talk, and to share important information." This included "both the women themselves (when important information was held back), but also the immediate and wider team." Another team member talked about the challenges associated with "fixed positions, and inflexible views" about a woman, and her circumstances, and the difficulties they experienced when they "get caught between opposing factions" also featured. One of the greatest tests for this team, were the times when they assessed others practice as "lacking compassion." "Reactive practice" was also a problem with the value of being given "enough time" being highly valued.

What became possible with time was expressed; WHSW explaining that time was what protected the practice from being reactive. Midwives often describe pregnancy as a "window of opportunity" when women, faced with bringing new life into the world think about their lives differently, and therefore are more able to make different choices. In order to make the most of this window, women's health social workers talked about the value of "early referral" and the opportunities this afforded them. According to one team member time allowed them to "build relationships; engage in careful planning; develop a shared understanding of the issues." They also said that "time also provides a realistic opportunity to support the complex change that is needed before baby arrives."

\section{Discussion}

Although a particular model of care in women's health has not previously been articulated as an accepted standard of practice, a remarkably consistent and coherent account of practice has emerged from this study. The study created an opportunity to introduce a model of care that reflects a welfare orientation to practice in the WHSW team. Striving to develop a high quality relationship has been identified as important when social workers are engaging with people who are vulnerable (Trevithick, 2003). In the circumstance that the woman is pregnant and child welfare issues exist, the proposition is that by investing in and attending to the relationship with women, high standards of care, and purposefully 
maintaining an environment in which excellence can flourish (Braithwaite \& Travaglia, 2008) positive outcomes can be achieved. This emerged as a balancing act in this study.

It furthermore emerged from this study that there is a huge reliance on a practice environment (a safety net) that supports practitioners' ability to reflect on practice, and be guided by professional codes and the evidence and policy guidelines at their disposal. Accepting the complexity and uncertainty associated with social work practice, Ruch maintains that RBP relies on practitioners "developing and sustaining supportive professional relationships in unique and challenging situations" (Ruch, 2005, p. 113). In the provision of maternity services, midwives rely on a partnership model (New Zealand College of Midwives (Inc), 2016); also placing great emphasis on the relationship they have with pregnant women. This stresses the findings in the audit which emphasised the value WHSW placed on relationships with multiple stakeholders. In this practice arena the ability to not only gain and maintain the trust of women, but also that of midwifery colleagues, seems to be an absolute imperative. Ruch also argues that if relationship based practice is to flourish - the anxiety and uncertainty associated with the emotionally challenging nature of practice must be effectively addressed (2005). The practice is also dependent on safe and reflective supervisory space in order to develop appropriate responses to the anxiety and uncertainty referred to by Ruch (2005).

Situating practice within a neoliberal context, Lonne et al. (2009) have proposed that the dominant approach to improving outcomes for children has been an increased focus on the management of practice. They suggest however that what is needed "... is a theoretical and practice framework that articulates the links between values, theory, practice, evidence, and outcomes for children and their families" (Lonne et al., 2009 , p. 13). We argue that the model that emerged from this study goes some way to achieving this. However, it is within this context that WHSWs are forced to navigate one of the central tenets of the dominant child protection orientated approaches to practice, often described as the provision of child-centric practice (New Zealand Government, 2015). This article critiques this description and highlights the risk that this orientation is perceived as a one size fits all concept, not able to be contested or challenged. In a maternity context - where the woman and child are one being practitioners are required to engage with the health and welfare of them both. How this is managed in situations where there is often a significant history of previous harm to other children, is a challenge that requires careful and considered navigation.

\section{Conclusion}

Considering all the above, it is argued that the binary either/or positions of adopting a child centred or a woman's centred approach to practice should be avoided and an and / both orientation be adopted. This is true for a range of international contexts and the views of various authors support this dual orientation (Featherstone et al., 2014; Ferguson, 2001, 2003; Gould \& Baldwin, 2006; Keddell, 2014; Laing \& Humphreys, 2013; Lonne et al., 2009). From the findings presented in this article, it is clear that such an approach enables RBP and allows practitioners to assess the risks associated with the complex social factors a pregnant woman is experiencing in partnership with other stakeholders, including midwifery, medical and multiagency colleagues. This practice activity is complicated, challenging, nuanced, culturally informed and by its very nature, an exceedingly difficult task! However, the evidence suggests that getting this right in the maternity environment delivers multiple benefits for multiple stakeholders. 


\section{References}

Barnes, H., Barnes, A., Baxter, J., Crengle, S., Pihama, L., Ratima, M., \& Robson, B. (2013). Hapu ora: Wellbeing in the early stages of life. Retrieved from http://www. massey.ac.nz/massey/learning/departments/centresresearch/shore/projects/hapu-ora.cfm

Beddoe, L. (2014). Risk and vulnerability discourses in health. In L. Beddoe \& J. Maidment (Eds.), Social work practice for promoting health and wellbeing (pp. 51-62). New York: Routledge.

Bird, J. (2000). The heart's narrative. Therapy and navigating life's contradictions. Auckland: Edge Press.

Blumenfield, S., \& Epstein, I. (2001). Introduction: Promoting and maintaining a reflective professional staff in a hosptial-based social work department. Social Work in Health Care, 33(3/4), 1-13.

Braithwaite, J., \& Travaglia, J. (2008). An overview of clinica governance policies, practices and initiatives. Australian Health Review, 32(1), 10-22.

Bywaters, P. (2014). Globalisation, social work and health. In L. Beddoe \& J. Maidment (Eds.), Social work practice for promoting health and wellbeing (pp. 28-38). Oxon: Routledge.

Bywaters, P., McLeod, E., \& Napier, L. (Eds.). (2009). Social work and global health inequalities. Bristol: The Policy Press.

Creswell, J., \& Plano Clark, V. (2011). Designing and conducting mixed methods research. Los Angeles: Sage Publications.

Dobbs, T., \& Eruera, M. (2014). Kaupapa Maori wellbeing framework: The basis for whanau violence prevention and intervention. Auckland, New Zealand: New Zealand Family Violence Clearinghouse, University of Auckland.

Fargion, S. (2014). Synergies and tensions in child protection and parent support: Policy lines and practitioners' cultures. Child and Family Social Work, 19(1), 24 - 33.

Featherstone, B., White, S., \& Morris, K. (2014). Re-imagining child protection towards humane social work with families. Bristol: Policy Press.

Ferguson, H. (2001). Promoting child protection, welfare and healing: The case for developing best practice. Child and Family Social Work, 6, 1-12.

Ferguson, H. (2003). Outline of a critical best practice perspective on social work and social care. British Journal of Social Work, 33, 1005-1024.

Gilbert, N., Parton, N., \& Skivenes, M. (2011). Child protection systems: International trends and orientations. Oxford: Oxford University Press.

Gould, N., \& Baldwin, M. (Eds.). (2006). Social work, critical reflection and the learning organization. Aldershot: Ashgate.

Handcock, J. (2013). Legislation to reduce child poverty. Retrieved from http://www.occ.org.nz/assets/ Publications/OCC-Summary-Sheet-Legislating-toReduce-Child-Poverty.pdf

Haultain, L. (2011). From the cleaners to the doctors exploring the dimensions of effective health social work in the acute hospital. (Doctoral thesis, Massey University Albany, Auckland, New Zealand). Retrieved from http://mro.massey.ac.nz/handle/10179/3255
Haultain, L. (2014). Facing the challenges together: A future vision for health social work. In L. Beddoe \& J. Maidment (Eds.), Social work practice for promoting health and wellbeing (pp. 39-50). Oxton: Routledge.

Hyslop, I. (2009). Child protection policy and practice: A relationship lost in translation. Social Policy Journal of New Zealand Te Puna Whakaaro. (34), 62-72.

International Federation of Social Workers. (2008). International policy on health. Retrieved 22 April, 2011, from http://www.ifsw.org/p38000081.html

Keddell, E. (2014). The ethics of predictive risk modelling in aotearoa/new zealand child welfare context: Child abuse prevention or neo-liberal tool? Critical Social Policy, 1-20.

Lachman, P., \& Bernard, C. (2006). Moving from blame to quality: How to respond to failures in child protection services. Child Abuse \& Neglect. (30), 963-968.

Laing, L., \& Humphreys, C. (2013). Social work and domestic violence developing critical thinking \& reflective practice. London: SAGE publications Ltd.

Lonne, B., Parton, N., Thomson, J., \& Harries, M. (2009). Reforming child protection. London: Routledge.

Munro, E. (2011). The Munro review of child protection. Interim report: The child's journey. London: Department of Education. Retrieved from http://www.education.gov.uk/ munroreview/downloads/Munrointerimreport.pdf.

New Zealand Government. (2015). Children's action plan he taonga te tamariki. Wellington: New Zealand Government.

O'Brien, M. (2015, 1 February 2016). The latest: Prevention: The best way to address child poverty. Auckland: Child Poverty Action Group. Retrieved from http://www.cpag. org.nz/resources-publications/background-papers-1/

Rashbrooke, M. (Ed.). (2013). Inequality a New Zealand crisis. Wellington: Bridget Williams Books Limited.

Ruch, G. (2005). Relationship-based practice and reflective practice: Holistic approaches to contemporary child care social work. Child and Family Social Work, 10, 111-123.

Thomas, D. (2006). A general inductive approach for analyzing qualitative evaluation data. American Journal of Evaluation, 27(2), 237-246.

Trevithick, P. (2003). Effective relationship-based practice: A theoretical exploration. Journal of Social Work Practice, 17(2), 164-176.

Turnell, A. (1989). Aspiring to partnership: The signs of safety approach to child protection. Paper presented at the Twelfth international congress on child abuse and neglect, Auckland. 